\title{
Desenvolvimento morfológico dos ovários em fetos eqüinos sem raça definida
}

\author{
Morphological development of ovaries in fetuses of cross-breed equines
}

\author{
Christiana Savastano Naves ${ }^{\mathrm{I}}$ Rogério Chaves VieiraII Elmo Gomes Diniz ${ }^{\mathrm{II}}$ \\ José Octávio Jacomini ${ }^{\text {II }}$ Marcelo Emílio Belleti ${ }^{\text {III }}$ Rafael Carvalho de Oliveira ${ }^{\mathrm{IV}}$
}

\section{RESUMO}

O objetivo deste trabalho foi caracterizar histologicamente o desenvolvimento ovariano pré-natal em fetos eqüinos sem raça definida (SRD) nos trópicos, ressaltando surgimento e quantificação de ovogônias e folículos. Foram obtidos 131 fetos em frigorífico, os quais foram mensurados quanto ao comprimento (cm) equivalente à distância cefalococcígea (CR), seguido de corte das gônadas e fixação das amostras em Bouin por 24 horas. As idades foram estimadas por regressão. Foram preparados cortes histológicos ovarianos de $7 \mu \mathrm{m}$ de espessura, os quais foram corados com hematoxilina-eosina. O surgimento de ovogônias, folículos primordiais, em crescimento e antrais foi verificado, respectivamente, em fetos com $C R$ entre 4,1 e $6,5 \mathrm{~cm}$ (40 a 49 dias de gestação (DG)); 9,1 e 12,0cm (60 a $69 \mathrm{DG}) ; 23,1$ e $29,0 \mathrm{~cm}$ (116 a $135 \mathrm{DG})$ e 50,1 e 65,0cm (201 a $245 \mathrm{DG})$. A quantidade máxima de ovogônias, folículos primordiais, em crescimento e antrais foi observada em fetos com CR entre, 4,1 e 6,0cm (40 a $49 \mathrm{DG}) ; 16,1$ e 23,0cm (90 a $115 \mathrm{DG}) ; 29,1$ e $36,0 \mathrm{~cm}$ (136 a $155 \mathrm{DG})$ e 50,1 e 97,0cm (201 a $320 \mathrm{DG})$, respectivamente. Os resultados sugerem que o desenvolvimento morfológico dos ovários fetais de eqüinos SRD nos trópicos é mais precoce que o observado nos relatos de literatura referentes a estudos de eqüinos de diversas raças em regiões temperadas.

Palavras-chave: eqüinos, fetos, ovários, desenvolvimento gonadal.

\section{ABSTRACT}

This research research was aimed at histologically characterizing the pre-natal ovarian development of crossbreed equine fetuses in the tropics, observing the rise and the quantification of oogonia and follicles. One hundred and thirty one fetuses were obtained from a slaughterhouse, their crownrump length (CRL) was measured in centimeters (cm). Next, the gonads were sectioned and the samples were placed to rest in Bouin's liquid for 24 hours. The ages were estimated by regression. $7 \mu \mathrm{m}$ thick histological ovarian cuts were prepared and stained with hematoxylin-eosin. Oogonia, primordial, growing and antral follicles were observed in fetuses whose CRL was between 4.1 and $6.5 \mathrm{~cm}$ (40 to 49 gestation days $(G D)) ; 9.1$ and $12.0 \mathrm{~cm}(60$ to $69 \mathrm{GD}) ; 23.1$ and $29.0 \mathrm{~cm}(116$ to $135 \mathrm{GD}$ ); 50.1 and $65.0 \mathrm{~cm}$ (201 to $245 \mathrm{GD}$ ) respectively. The maximum amount of oogonia and of primordial, growing and antral follicles occurred in fetuses whose CRL was between 4.1 and $6.0 \mathrm{~cm}$ (40 to $49 \mathrm{GD}$ ); 16.1 and $23.0 \mathrm{~cm}$ (90 to 115 $G D) ; 29.1$ and $36.0 \mathrm{~cm}$ (136 to $155 \mathrm{GD}) ; 50.1$ and $97.0 \mathrm{~cm}$ (201 to $320 G D)$, respectively. These results suggest that the development of cross-breed equine ovarian fetuses in the tropics is more premature than that described in the literature on studies of various equine breeds in temperate regions.

Key words: equine, fetuses, ovaries, gonadal development.

\section{INTRODUÇÃO}

Conhecimentos sobre a embriologia dos órgãos reprodutivos são indispensáveis para se entender a patogenia de muitas anomalias das gônadas e estruturas acessórias. No caso do ovário eqüino, este difere daqueles de outras espécies de mamíferos domésticos por desenvolver modificações expressivas durante a fase fetal, apresentar fossa ovárica, parte central do parênquima correspondente ao tecido

IAutônoma. Endereço para correspondência: Rua Jamil Tannús, 864, Bairro Altamira, 38400-134, Uberlândia, MG, Brasil. E-mail: christiananaves@gmail.com.

IIFaculdade de Medicina Veterinária, Universidade Federal de Uberlândia (UFU), Uberlâdia, MG, Brasil.

IIIInstituto de Ciências Biomédicas, UFU, Uberlândia, MG, Brasil

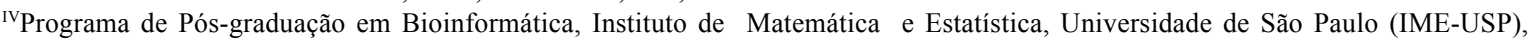
São Paulo, SP, Brasil . 
cortical, abundante estroma fibroso e conter, freqüentemente, tecido adrenocortical ectópico (McENTEE, 1993). Deste modo, a estrutura, funções e distúrbios do ovário eqüino só podem ser entendidos se o desenvolvimento pré-natal da gônada for conhecido.

As gônadas de eqüinos na fase pré-natal atraem interesse devido ao seu tamanho expressivo, resultante do elevado número de células intersticiais. Tem-se conhecimento da existência de marcante semelhança entre células luteais, hepáticas e intersticiais das gônadas de fetos dessa espécie e também, que as gônadas de fetos eqüinos de 7 a 8 meses são maiores do que os ovários da égua no mesmo período de gestação (GINTHER, 1992).

Os primeiros estudos e descrições histológicas das gônadas fetais eqüinas foram realizados por COLE et al. (1933), os quais associaram o desenvolvimento da gônada fetal com a condição dos ovários maternos e concentrações hormonais plasmáticas nas éguas. Diversas pesquisas têm sido associadas com a morfologia das estruturas ovarianas fetais (GONZÁLEZ-ÂNGULO et al., 1975; HAY \& ALLEN, 1975; MERCHANT-LARIOS, 1979), aspectos bioquímicos (GINTHER, 1987; HAY \& ALLEN, 1975) e desenvolvimento celular (DEANESLY, 1975; 1977; GINTHER, 1979; WALT et al., 1979).

As gônadas originam-se de espessamentos conhecidos como cristas gonádicas, que se formam no terço médio dos ductos mesonéfricos. No embrião, as células germinativas primordiais migram do endoderma do saco vitelino para as cristas gonádicas e, logo após o término dessa migração, inicia-se a diferenciação gonadal, passando estas células a serem denominadas ovogônias ou espermatogônias. Na espécie eqüina, o processo de diferenciação gonadal ocorre entre 39 e 45 dias de gestação (DG) (GONZÁLEZ-ÂNGULO et al., 1971; MERCHANT-LARIOS, 1979).

Fenômenos que ocorrem durante o desenvolvimento embrionário e fetal terão seus efeitos, muitas vezes, observados apenas quando o animal alcança a puberdade. Isso posto, torna-se necessário amplo conhecimento acerca do comportamento de animais criados sob condições tropicais, surgindo especial interesse no desenvolvimento de pesquisas na área reprodutiva, sendo fundamental o início dos estudos pela origem e diferenciação dos órgãos sexuais.

Estudos sobre o desenvolvimento pré-natal das gônadas em eqüinos foram feitos, na sua maioria, em animais criados em condições temperadas, sendo inexistente trabalhos relacionados ao assunto envolvendo eqüinos criados sob clima tropical. Assim, este trabalho teve como objetivo caracterizar histologicamente o desenvolvimento morfológico ovariano pré-natal de fetos eqüinos sem raça definida nos trópicos, evidenciando o surgimento e quantificação de ovogônias e folículos primordiais, em crescimento e antrais.

\section{MATERIAL E MÉTODOS}

Foram utilizados 131 fetos de éguas gestantes sem raça definida, colhidos no Frigorífico Pomar Ltda situado em Araguari, MG. Estes foram medidos em comprimento $(\mathrm{cm})$, equivalente à distância cefalococcígea (CR) e identificados quanto ao sexo por observação macroscópica. Retirou-se um fragmento medial dos ovários fetais biseccionando-se transversalmente a gônada no seu terço médio, seguido de fixação em Bouin por 24 horas.

Após, as amostras foram colocadas em frascos contendo álcool a $50 \%$ por mais 24 horas e, posteriormente, transferidas para recipientes com álcool a $70 \%$, onde ficaram armazenadas até o momento da preparação histológica. As amostras foram seccionadas com micrótomo em cortes de $7 \mu \mathrm{m}$ de espessura, sendo que a cada $250 \mu \mathrm{m}$ coletaram-se três cortes, conforme a técnica descrita por VIGIER et al. (1976). Foi realizada a coloração dos cortes histológicos com hematoxilina-eosina de acordo com MICHALANY (1980), estando as lâminas prontas para análise em microscopia de luz.

Devido à escassez de dados em relação ao período de gestação dos animais desembarcados no frigorífico, os comprimentos fetais foram obtidos previamente à fixação das amostras. Diante dessas informações, calcula-se no presente trabalho a fórmula de regressão, $\mathrm{DG}=22,623+4,2528 \mathrm{CR}-0,0124 \mathrm{CR}^{2}\left(\mathrm{r}^{2}=\right.$ $0,98)$, para estimativa da idade gestacional, utilizandose o software S-Plus ${ }^{\circledR}$ Professional (2000). A partir desta equação, os fetos foram distribuídos em classes, em função da CR e DG, como demonstrado na tabela 1 .

Os cortes histológicos foram analisados por microscópio de luz Olympus BX40 e os resultados expressos por área ovariana de $1000 \mu \mathrm{m}^{2}$. O ovário fetal da espécie eqüina, por apresentar características particulares, não possibilitou calcular o número das várias estruturas por volume ovariano total, devido ao fato das proporções da cortical e medular se modificarem constantemente durante o decorrer da gestação. A documentação fotográfica para tipificação e quantificação das estruturas ovarianas (ovogônias e folículos primordiais, em crescimento e antrais), foram realizadas por meio do software HLimage++97, sendo as imagens digitalizadas com aumento de 800x. 
Tabela 1 - Fetos eqüinos sem raça definida distribuídos em função da distância cefalococcígea (CR) e dias de gestação.

\begin{tabular}{lll}
\hline Número de amostras & CR $(\mathrm{cm})$ & DG (dias) \\
\hline 12 & $4,1-6,5$ & $40-49$ \\
15 & $6,6-9,0$ & $50-59$ \\
12 & $9,1-12,0$ & $60-69$ \\
13 & $12,1-16,0$ & $70-89$ \\
13 & $16,1-23,0$ & $90-115$ \\
18 & $23,1-29,0$ & $116-135$ \\
10 & $29,1-36,0$ & $136-155$ \\
08 & $36,1-50,0$ & $156-200$ \\
09 & $50,1-65,0$ & $201-245$ \\
05 & $65,1-81,0$ & $246-280$ \\
16 & $81,1-97,0$ & $281-320$ \\
\hline
\end{tabular}

\section{RESULTADOS E DISCUSSÃO}

Devido à falta de dados em relação ao período gestacional das fêmeas abatidas no frigorífico onde as amostras fetais foram coletadas, optou-se por mensurar a $\mathrm{CR}$ dos fetos, com a expectativa de conseguir ajustar as medidas ao gráfico adaptado de BERGIN et al. (1967), o qual estima a idade gestacional a partir da CR. Como não foi possível esta adaptação, os resultados foram descritos apenas em CR, assim como no trabalho de GONZÁLEZ-ÂNGULO et al. (1971) e MERCHANT-LARIOS (1979), os quais também utilizaram amostras obtidas de fêmeas abatidas em frigorífico. Por outro lado, não houve como comparar os resultados obtidos neste trabalho àqueles de DEANESLY (1975), HAY \& ALLEN (1975) e WALT et al. (1979), os quais descreveram seus resultados em DG, por obterem suas amostras a partir de laparotomia ou necropsia das fêmeas após data da cobertura controlada. Contudo, baseado no modelo de gráfico de BERGIN et al. (1967), desenvolveu-se neste trabalho uma fórmula de regressão, possibilitando a descrição dos resultados simultaneamente em DG e CR. Cumpre ressaltar ainda que, a comparação entre autores fica comprometida, pois segundo BERGIN et al. (1967), nenhum relato da embriologia eqüina é fundamentado ou justificado completamente, além do que detalhamentos em fetos da mesma idade gestacional variam mais do que $50 \%$, devido às diferenças nas técnicas, variações entre raças e problemas na determinação da idade fetal.

Neste trabalho, as ovogônias foram encontradas em todas as amostras com CR superior a $4,1 \mathrm{~cm}$ (40 DG), sempre limitadas à região cortical, localizada na periferia das gônadas, fato também observado por GINTHER (1992). Isto comprova a divisão do ovário fetal eqüino entre camadas cortical e medular desde a distinção sexual macroscópica até próximo ao nascimento, embora estas regiões ainda não se apresentem invertidas no estroma ovariano como em fêmeas adultas.

Como exposto na tabela 2, as ovogônias puderam ser observadas em vários estágios gestacionais, sendo que com o desenvolvimento fetal a quantidade destas células diminui progressivamente. Estas estruturas foram encontradas organizadas em camadas ou agrupadas em cordões celulares dentro do córtex ovariano (Figura 1).

As ovogônias apresentaram-se em número expressivo até em fetos com CR entre 9,1 e 12,0cm (60 a 69 DG). Em fetos com CR entre 16,1 e 23,0cm (90 a 115 DG) o número dessas células começou a diminuir gradativamente até desaparecerem naqueles com CR entre 65,1 e $81,0 \mathrm{~cm}$ (246 a 280 DG). Esses dados contrapõem-se aos achados por DEANESLY (1977), que verificaram número crescente de ovogônias por volta de $102 \mathrm{DG}$.

Os relatos de GONZÁLEZ-ÂNGULO et al. (1971) demonstram que aos 150 DG poucas ovogônias são encontradas. Neste trabalho, ao contrário, tais células foram identificadas em número substancial, considerando-se a mesma fase gestacional. DEANESLY (1977) citou que aos 75, 100, 120 e de 150 a 197 DG, as ovogônias são comuns, com subseqüente diminuição entre 200 e 207 DG, fato calcado na hipótese de que em eqüinos o impulso ovogênico desaparece gradualmente por volta de $210 \mathrm{DG}$. Semelhantemente, foi observado nesta investigação que o número de ovogônias diminuiu lentamente a partir de fetos com CR entre 12,1 e $16,0 \mathrm{~cm}$ (70 a 89 DG), verificando-se brusca redução nos ovários de fetos com CR entre 36,1 e 65,0cm (156 a 245 DG) e completo desaparecimento a partir dessa fase (Tabela 2).

Neste experimento, as ovogônias diminuíram em número a partir de amostras com $\mathrm{CR}$ entre 9,1 e 12,0cm (60 a 69 DG), e foram encontradas em pequena quantidade nos ovários de fetos com $\mathrm{CR}$ entre 29,1 e 36,0 cm (136 a 155 DG). Em contrapartida, DEANESLY (1977) encontrou ovogônias em maior atividade aos $150 \mathrm{DG}$. Este fato pode ser explicado por provável diminuição da atividade mitótica das ovogônias e possível início de apoptose celular.

Nos fetos com CR entre 9,1 e 12,0cm (60 a 69 DG), observaram-se ovócitos sendo contornados por células foliculares planas, com a conseqüente formação dos folículos primordiais (Figura 2). Pela análise da tabela 2, verifica-se que o número de folículos primordiais aumentou gradativamente nas gônadas fetais com CR entre 12,1 e 16,0 cm (70 a 89 DG), com a fase de CR entre 23,1 e 29,0cm (116 a 135 DG) 
Tabela 2 - Valores médios do número de ovogônias (OG), folículos primordais (FP), em crescimento (FC) antrais (FA), por área média de $1000 \mu \mathrm{m}^{2}$, em função da distância cefalococcígea (CR) e dias de gestação (DG), em ovários de fetos eqüinos sem raça definida.

\begin{tabular}{|c|c|c|c|c|c|c|c|c|c|c|c|}
\hline \multicolumn{12}{|c|}{ Distância Cefalococcígea e Dias de Gestação } \\
\hline $\mathrm{CR}(\mathrm{cm})$ & $4,1-6,5$ & $6,6-9,0$ & $9,1-12,0$ & $12,1-16,0$ & $16,1-23,0$ & $23,1-29,0$ & $29,1-36,0$ & $36,1-50,0$ & $50,1-65,0$ & $65,1-81,0$ & $81,1-97,0$ \\
\hline $\begin{array}{l}\text { DG } \\
\text { (dias) }\end{array}$ & $40-49$ & $50-59$ & $60-69$ & $70-89$ & $90-115$ & $116-135$ & $136-155$ & $156-200$ & $201-245$ & $246-280$ & $281-320$ \\
\hline $\mathrm{N}^{*}$ & 12 & 15 & 12 & 13 & 13 & 18 & 10 & 08 & 09 & 05 & 16 \\
\hline OG & $\begin{array}{c}3,78 \\
( \pm 0,94)\end{array}$ & $\begin{array}{c}2,78 \\
( \pm 0,43)\end{array}$ & $\begin{array}{c}2,78 \\
( \pm 0,46)\end{array}$ & $\begin{array}{c}2,27 \\
( \pm 0,77)\end{array}$ & $\begin{array}{c}1,59 \\
( \pm 0,68)\end{array}$ & $\begin{array}{c}1,32 \\
( \pm 0,78)\end{array}$ & $\begin{array}{c}1,29 \\
( \pm 0,63)\end{array}$ & $\begin{array}{c}0,73 \\
( \pm 0,45)\end{array}$ & $\begin{array}{c}0,55 \\
( \pm 0,30)\end{array}$ & & \\
\hline FP & & & $\begin{array}{c}0,40 \\
( \pm 0,29)\end{array}$ & $\begin{array}{c}0,80 \\
( \pm 0,50)\end{array}$ & $\begin{array}{c}1,04 \\
( \pm 0,39)\end{array}$ & $\begin{array}{c}0,99 \\
( \pm 0,41)\end{array}$ & $\begin{array}{c}0,81 \\
( \pm 0,42)\end{array}$ & $\begin{array}{c}0,67 \\
( \pm 0,41)\end{array}$ & $\begin{array}{c}0,53 \\
( \pm 0,35)\end{array}$ & $\begin{array}{c}0,42 \\
( \pm 0,18)\end{array}$ & $\begin{array}{c}0,24 \\
( \pm 0,11)\end{array}$ \\
\hline $\mathrm{FC}$ & & & & & & $\begin{array}{c}0,10 \\
( \pm 0,00)\end{array}$ & $\begin{array}{c}0,10 \\
( \pm 0,00)\end{array}$ & $\begin{array}{c}0,13 \\
( \pm 0,58)\end{array}$ & $\begin{array}{c}0,29 \\
( \pm 0,14)\end{array}$ & $\begin{array}{c}0,28 \\
( \pm 0,12)\end{array}$ & $\begin{array}{c}0,29 \\
( \pm 0,12)\end{array}$ \\
\hline FA & & & & & & & & & $\begin{array}{c}0,10 \\
( \pm 0,00)\end{array}$ & $\begin{array}{c}0.10 \\
( \pm 0,00)\end{array}$ & $\begin{array}{c}0,10 \\
( \pm 0,20)\end{array}$ \\
\hline
\end{tabular}

* número de amostras em cada classe de distância cefalococcígea ou período gestacional.

caracterizada pelo início da diminuição dos mesmos, atingindo os menores valores nos fetos com CR entre 81,1 e $97,0 \mathrm{~cm}$ (281 a 320 DG).
Os folículos primordiais apresentaram-se em números máximo e mínimo nas amostras com CR entre 16,1 e 23,0cm (90 a 115 DG) e 81,1 e 97,0cm (281 a 320

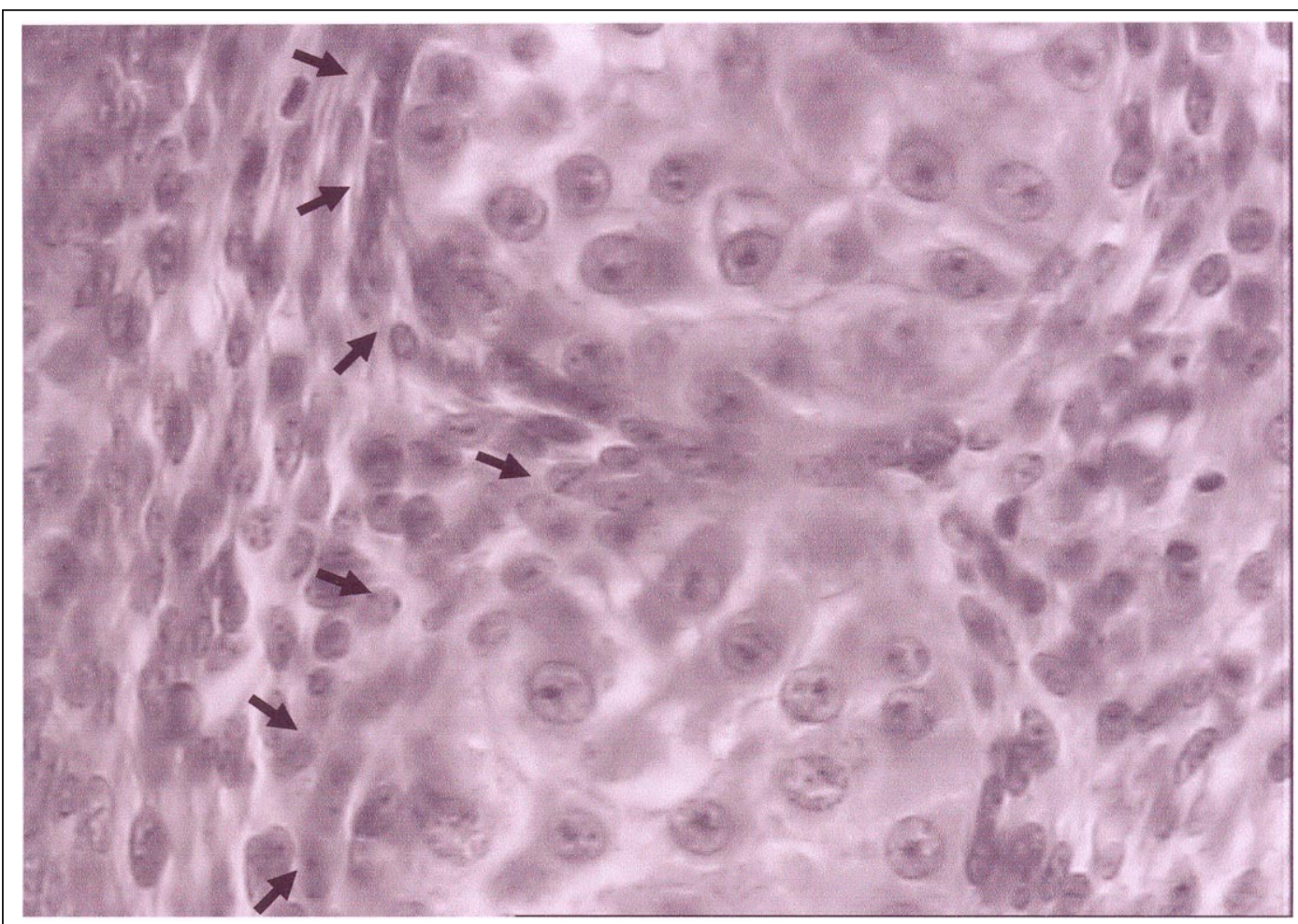

Figura 1 - Fotomicrografia de corte histológico de ovário de feto eqüino sem raça definida. Setas delimitam os ninhos de ovogônias. HE. Aumento 800x. 


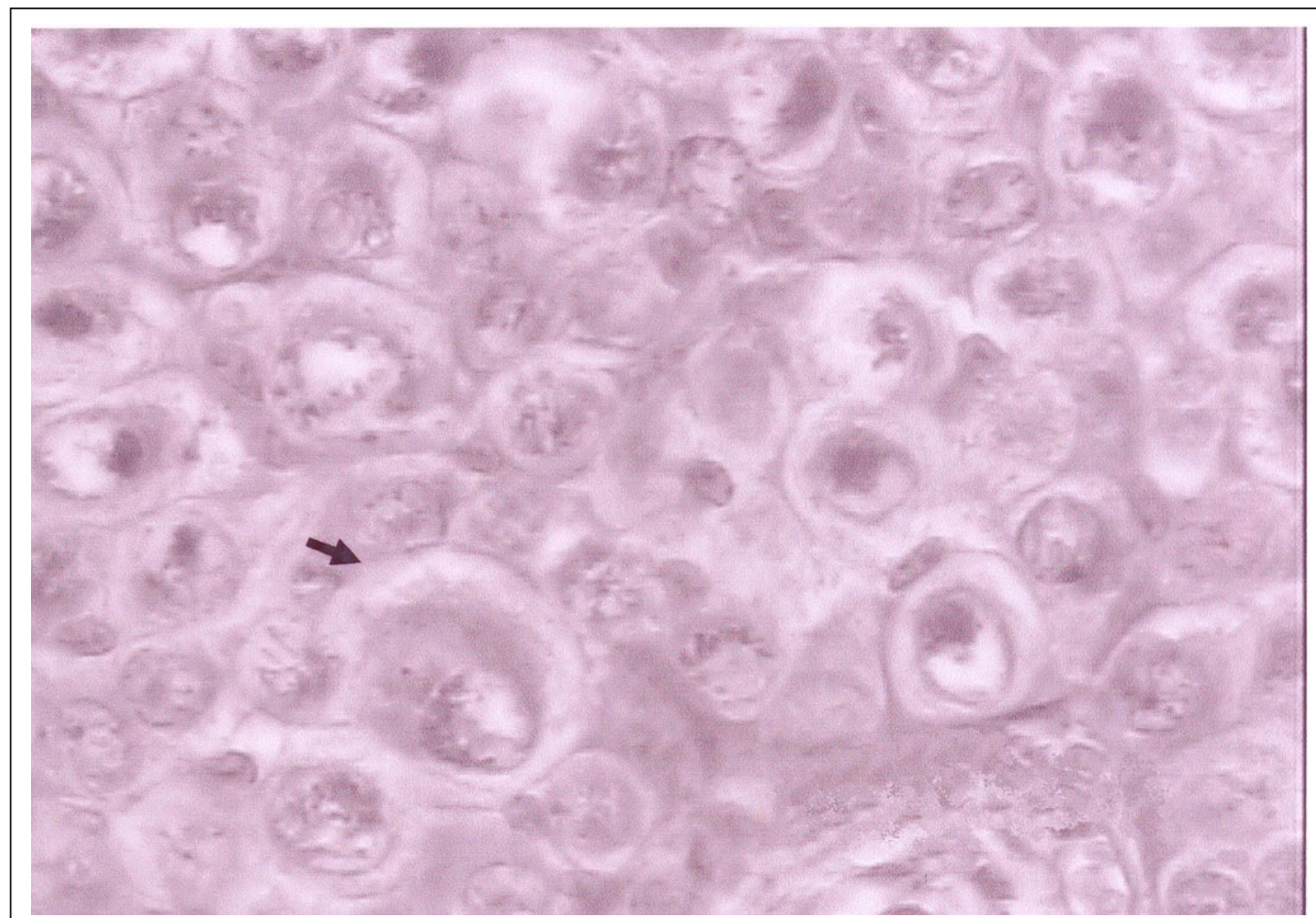

Figura 2 - Fotomicrografia de corte histológico de ovário de feto eqüino sem raça definida. Observa-se folículo primordial (seta) com ovócito contornado por células foliculares planas. HE. Aumento 800x.

DG), respectivamente (Tabela 2). Esses achados discordam de DEANESLY (1975; 1977), que constatou presença freqüente de folículos primordiais aos $150 \mathrm{e}$ 300 DG e rara aos $75,102,116,197,200$ e 207 DG. Isto caracteriza formação folicular antecipada em relação ao descrito na literatura.

Neste trabalho, foram considerados folículos em crescimento (Figura 3) tanto aqueles contornados por camada única de células foliculares cúbicas (folículos primários) como também os envolvidos por mais de uma camada de células foliculares cúbicas (folículos secundários). Os folículos em crescimento foram primeiramente observados em fetos com CR entre 23,1 e 29,0 cm (116 a 135 DG), em pequeno número, período este inferior ao encontrado na investigação de DEANESLY (1977), que descreveu folículos primordiais em início de crescimento a partir de 275 DG, apresentando células cubóides formando camadas ao redor dos ovócitos. Nos fetos com CR entre 36,1 e $50,0 \mathrm{~cm}$ ( 156 a 200 DG) estes ainda foram verificados em número reduzido. O número desses folículos permaneceu baixo com o progredir do desenvolvimento fetal, alcançando o máximo em fetos com CR entre 50,1 e 97,0cm (201 a 320 DG). No estágio de CR entre 81,1 e $97,0 \mathrm{~cm}$ (281 a 320 DG) deste experimento, tais folículos apresentaram-se em número expressivo (Tabela 2), porém iniciaram crescimento mais precocemente em relação aos relatos da literatura.

Folículos secundários com evidência de formação de antro e folículos com antro totalmente formado (folículos terciários) (Figura 4) foram incluídos na categoria de folículos antrais. Detectaram-se os primeiros folículos antrais em ovários de fetos eqüinos com CR entre 50,1 e 65,0cm (201 a 245 DG) em pequeno número. Estes ainda puderam ser encontrados nos fetos com CR entre 65,1 e 81,0cm (246 a 280 DG) e entre 81,1 e $97,0 \mathrm{~cm}$ (281 a 320 DG) (Tabela 2). Os primeiros folículos antrais observados neste trabalho foram detectados em ovários de fetos eqüinos com $\mathrm{CR}$ entre 50,1 e $65,0 \mathrm{~cm}$ (201 a 245 DG), não se encontrando na literatura científica relatos referentes ao período gestacional em que esses freqüentemente aparecem. A presença de poucos folículos antrais no período prénatal pode ser uma característica da espécie eqüina, sendo que DEANESLY (1977), na sua pesquisa, identificou um único folículo antral.

Pode-se inferir que o número de amostras utilizadas neste trabalho é superior aos encontrados na literatura, por exemplo, HAY \& ALLEN (1975), os quais estudaram ovários de quatro fetos; GONZÁLEZÂNGULO et al. (1975), que analisaram gônadas de cinco fetos; DEANESLY (1975; 1977), o qual estudou 17 fetos; 


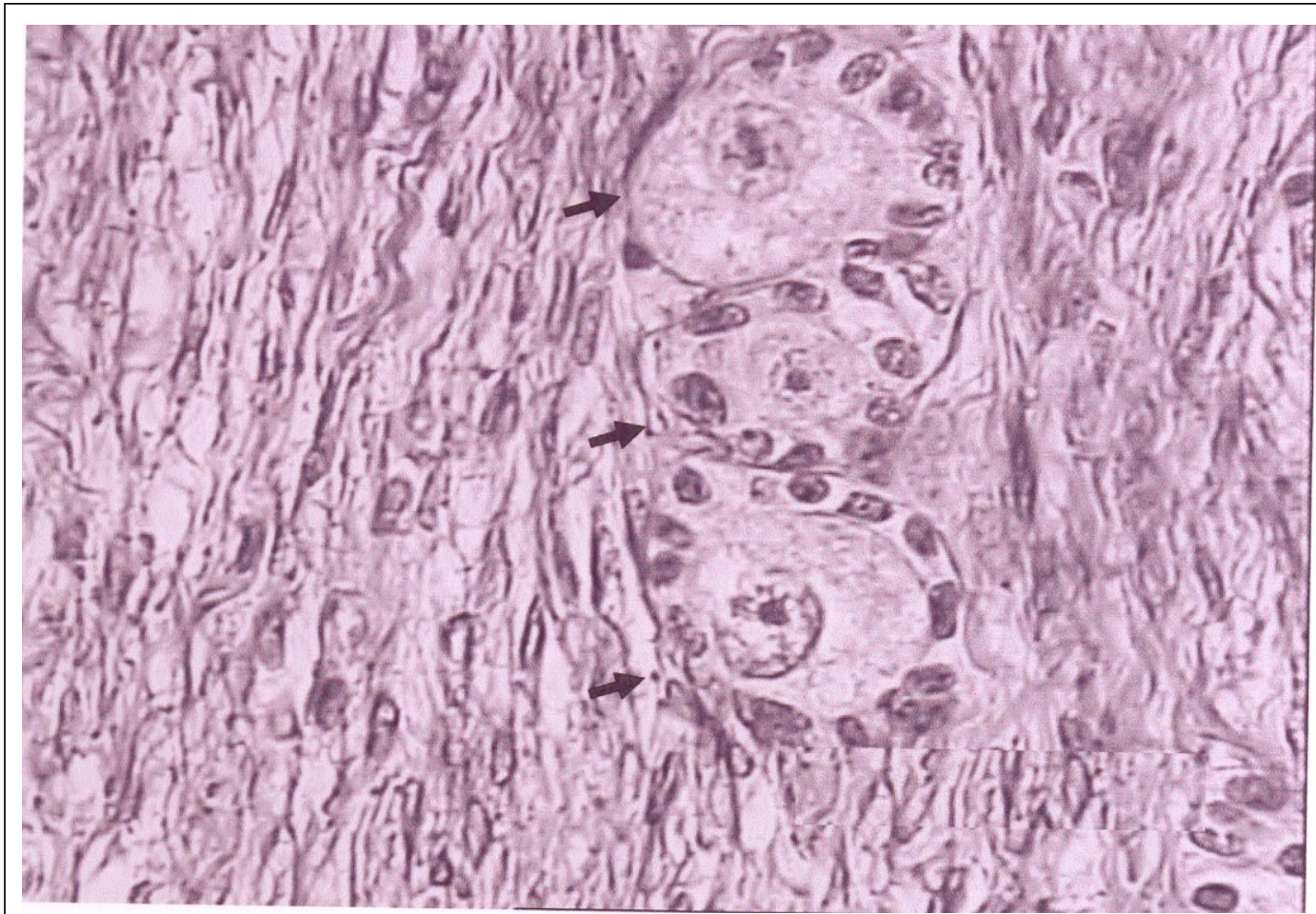

Figura 3 - Fotomicrografia de corte histológico de ovário de feto eqüino sem raça definida. Setas indicam folículos em crescimento com ovócitos contornados por células foliculares cúbicas. HE. Aumento 800x.

WALT et al. (1979), que trabalharam com 21 fetos e MERCHANT-LARIOS (1979), com 36 fetos. O número

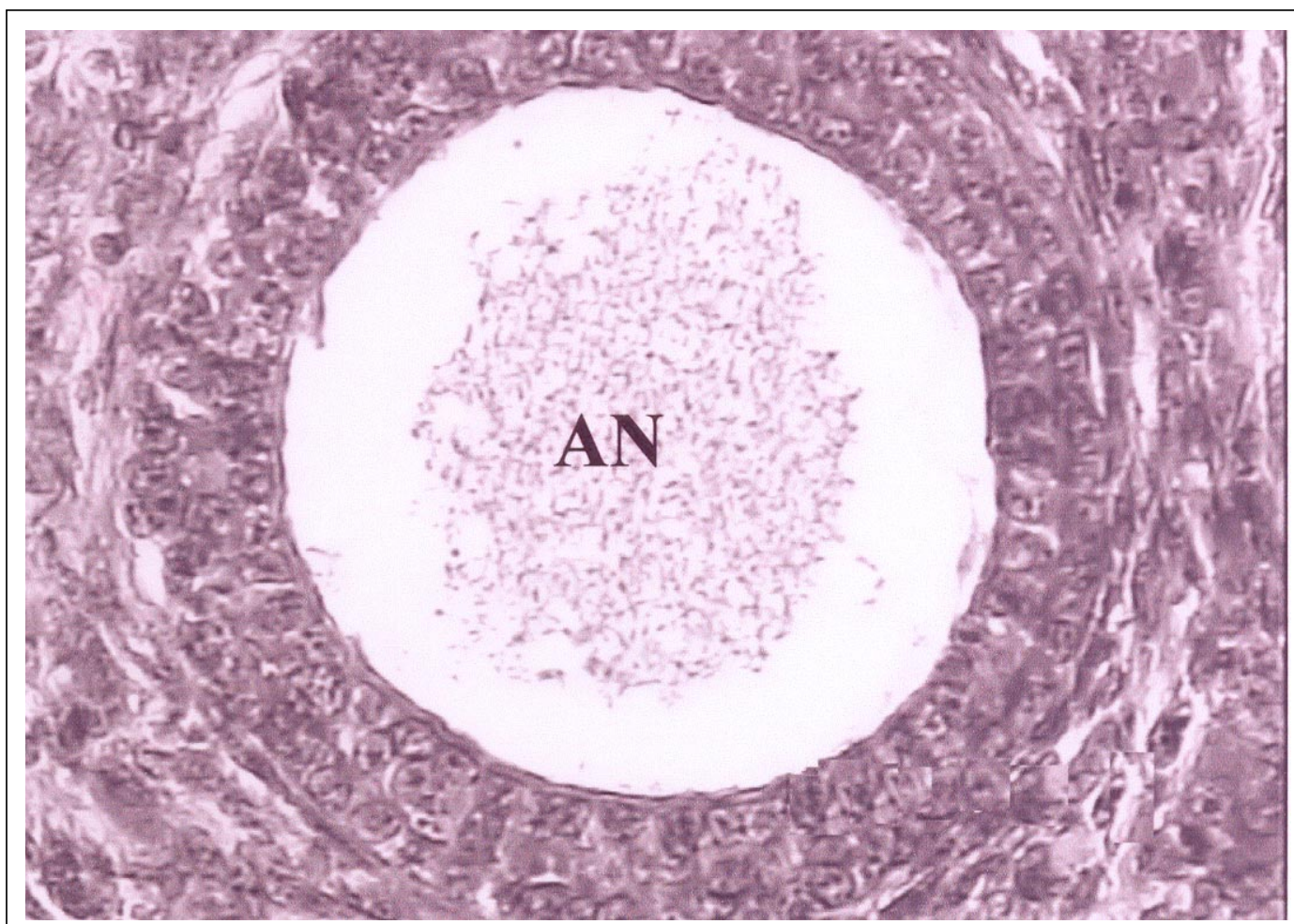

Figura 4 - Fotomicrografia de corte histológico de ovário de feto eqüino sem raça definida. Verifica-se folículo antral com boa definição histológica. Antro (AN). HE. Aumento 800x. 
de amostras utilizadas pode ter influenciado individualmente os valores médios obtidos em cada trabalho. É importante salientar que o elevado número de amostras nesta pesquisa, permitiu que o desenvolvimento ovariano pré-natal fosse descrito em todos os períodos gestacionais, o que não foi demonstrado nos trabalhos disponíveis na literatura.

\section{CONCLUSÕES}

O desenvolvimento morfológico dos ovários fetais de eqüinos sem raça definida nos trópicos ocorre antecipadamente em relação ao observado em estudos que utilizam raças de eqüinos criadas em regiões temperadas.

\section{REFERÊNCIAS}

BERGIN, W.C. et al. Developmental horizons and measurements useful for age determination of equine embryos and fetuses. In: ANNUAL CONVENTION, 1967, Lexington. Proccedings... Lexington: American Association of Equine Practitioners, 1967. p.179-196.

COLE, H. H. et al. The development and hormonal content of fetal horse gonads. Anatomical Record, New York, v.56, p.275-293, 1933.

DEANESLY, R. Germ cell development and the meiotic prophase in the fetal horse ovary. Journal of Reproduction and Fertility, Cambridge, Suppl. 23, p.547-552, 1975.

DEANESLY, R. Germ cell proliferations in the fetal horse ovary. Cell and Tissue Research, Heidelberg, v. 185, p.361$371,1977$.

GINTHER, O.J. Reproductive biology of the mare: basic and applied aspects. Cross Plains: Equiservices, 1979. 413p.

GINTHER, O.J. Relationships among number of days between multiple ovulations, number of embryos, and type of embryo fixation in mares. Journal of Equine Veterinary Science, Wildomar, v.7, p.82-88, 1987.

GINTHER, O.J. Reproductive biology of the mare: basic and applied aspects. 2.ed. Cross Plaines: Equiservices, 1992. p.397-403.

GONZÁLEZ-ÂNGULO, A. et al. Fine structure of gonads of the fetus of the horse (Equus caballus). American Journal of Veterinary Research, Schaumburg, v.32, p.1665-1676, 1971.

GONZÁLEZ-ÂNGULO, A. et al. Fine structure of the gonads of the horse and its functional implications. Journal of Reproduction and Fertility, Cambridge, Suppl. 23, p.563$567,1975$.

HAY, M.F.; ALLEN, W.R. An ultrastructural and histochemical study of the intersticial cells in the gonads of the fetal horse. Journal of Reproduction and Fertility, Cambridge, Suppl. 23, p.557-561, 1975.

McENTEE, K. Embryology of the reproductive organs. In:______ Reproductive pathology of domestic mammals. New York: Academic, 1993. Chapt.1, p.1-7.

MERCHANT-LARIOS, H. Ultrastructural events in horse gonadal morphogenesis. Journal of Reproduction and Fertility, Cambridge, Suppl. 27, p.479-485, 1979.

MICHALANY, J. Técnica histológica em anatomia patológica com instruções para o cirurgião, enfermeira e citotécnico. São Paulo: EPU, 1980. 277p.

S-PLUS ${ }^{\circledR} 2000$ PROFESSIONAL: software de análise e modelagem de dados. 3.ed. Basingstoke: Insightful Corporation, 2000. Acesso em: 19 jul. 2004. on line. Disponível em: <http:www.insightful.com.br>.

VIGIER, B. et al. Chronologie du dévelopement de l'appareil génital du foetus de veau. Archieves D'anatomie, Microscopy, Morphology and Experiment, Dijon, v.65, p.77-101, 1976.

WALT, M.L. et al. Development of the equine ovary and ovulation fossa. Journal of Reproduction and Fertility, Cambridge, Suppl. 27, p.471-477, 1979. 